\title{
Improving the efficiency of the road junction at the city entrance
}

\author{
A. G. Shevtsova ${ }^{1, *}, A . G$. Burlutskaya ${ }^{1}, V . V$. Vasilieva $^{2}, K . V$. Levshina $^{2}$, and $E . M$. \\ Minaeva $^{2}$ \\ ${ }^{1}$ Belgorod State Technological University named after V.G. Shukhov, Belgorod, Russia \\ ${ }^{2}$ Orel State University named after I.S. Turgenev, Orel, Russia
}

\begin{abstract}
The article is devoted to the study of the method of increasing the capacity at the trans-tailor interchanges providing access to cities, using the example of Belgorod, by introducing the Ramp metering traffic light control system. 4 traffic interchanges at the entrances to the regional center were investigated, geometric parameters of the exits were evaluated. Based on geometric analysis, intensity calculations and time delays, the optimal area for implementing the Ramp metering system is selected.
\end{abstract}

\section{Introduction}

The occurrence of congestion at traffic interchanges on the outskirts of the city is a common situation, especially during peak hours. The capacity of road network sections is significantly reduced. Today, in order to improve transport processes, various modeling products are used and intelligent transport systems are being introduced [1,2]. It is necessary to influence the traffic flow by controlling exits, using technical means of traffic management (traffic lights, road signs, TPI), in order to regulate the number of vehicles entering or leaving the highway [3].

Exit management methods are designed to maintain a balance between motorway capacity and demand by maintaining optimal operation of the motorway. Exit controls are used to regulate travel on a specific ramp, such as introducing a partial travel restriction (on a schedule) or possibly a permanent restriction. This regulatory measure significantly reduces or even increases the speed of the motorway. On the other hand, exit management ensures smooth merging of flows at conflict points. The management of exit ramps affects the traffic patterns of vehicles that join the stream. Exit control methods are used to order the speed at which cars enter the highway.

There are 4 exit management strategies:

- restricted access to the exit: temporary or permanent;

- managing exits using a traffic light object (Ramp metering) [4,5,6,7];

- creating traffic priorities for a special group of vehicles;

- organization of vehicle queue management on the ramp.

* Corresponding author: shevcova-anastasiya@mail.ru 
The strategy of traffic light management of exits has proven itself well at transport interchanges and at city entrances. The presence of a traffic light object optimally supports the traffic parameters at the exit for a smoother and unhindered merging of flows. This is achieved by evenly alternating phases of regulation and the order of passing vehicles from the exit. Exit regulation also ensures that dense groups of autotransport vehicles that approach the motorway are divided into separate vehicles, allowing those vehicles to avoid confusion at the confluence points.

Ramp metering - the "motorway entrance control system" - is an effective method of traffic management in many countries around the world. This system is used at two-level interchanges in conditions where a less intensive traffic flow leaves one highway at a turn exit and tries to join traffic on another highway.

\section{Materials and methods}

In the Belgorod region, the level of motorization can be compared with the level of the Moscow region (314 vs. 347) [8], given the fact that the total length of roads in the Belgorod region is 3 times less [9]. On major urban highways, during peak hours, the performance of the road network (UDS) is significantly reduced in certain sections. these sections are usually highways leading from suburban areas to the city center, where demand is highest. In order to increase the productivity of the road network, two-level interchanges with ramp exits are organized at entrances in cities. In order to increase the capacity in Belgorod, it is planned to introduce a Ramp metering system at two-level interchanges at the entrances to the city.

For expedient implementation of the proposed method of traffic management Ramp metering on the studied sections, first of all, it is necessary to evaluate the geometric parameters of the considered ramps and compare these parameters with the recommended ones.

The main geometric criteria include:

1) radius of curvature at the gate;

2) ramp capacity, auth;

3) the length of the acceleration distance, $m$;

4) distance of confluence of the streams, $m$;

5) the width of the roadway at the junction of the ramp and the motorway, $\mathrm{m}$.

Let's consider the geometric parameters of each of the studied sections. Interchange in p. Reasonable is constructed according to the type of clover leaf (figure 1-a)). Isolation in the neighborhood Novosadove also has a full configuration of a cloverleaf (figure 1-b)). The third interchange leading to the city is a tube interchange in Northern (figure 1-c)). The fourth transport interchange under study, which provides the intersection of the M-2 highway and the road leading to the city, is a cloverleaf interchange (figure 1-d)).

Since Ramp metering is not used in the Russian Federation, there are no regulatory documents or requirements for it. We will use recommendations and sources from foreign countries on the ramp geometry for a comfortable flow merge. 


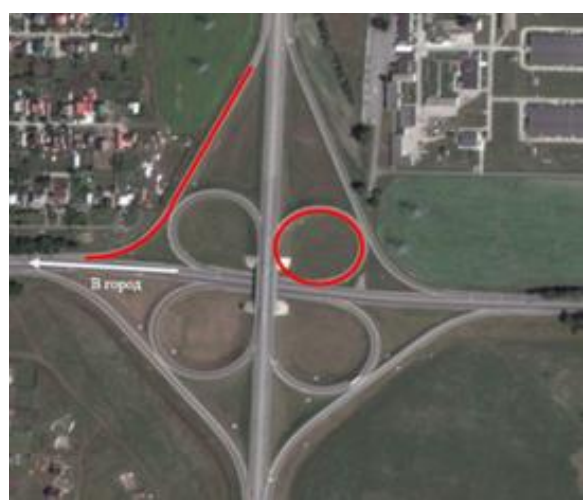

a)

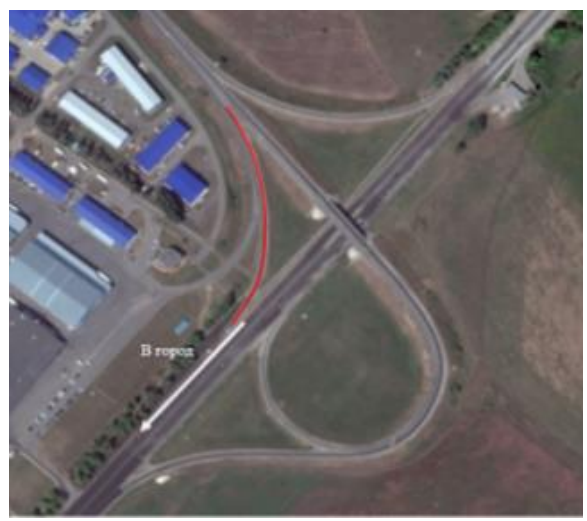

c)

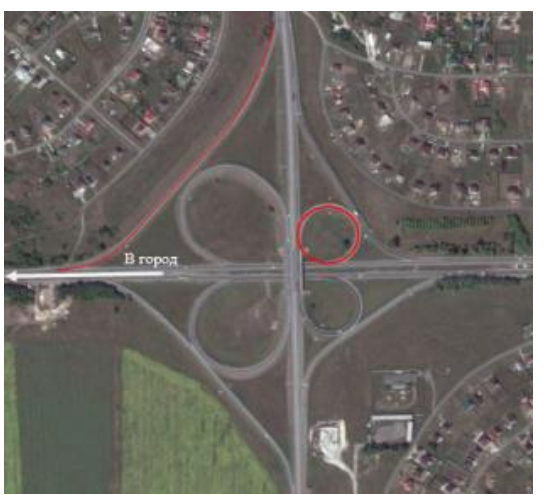

b)

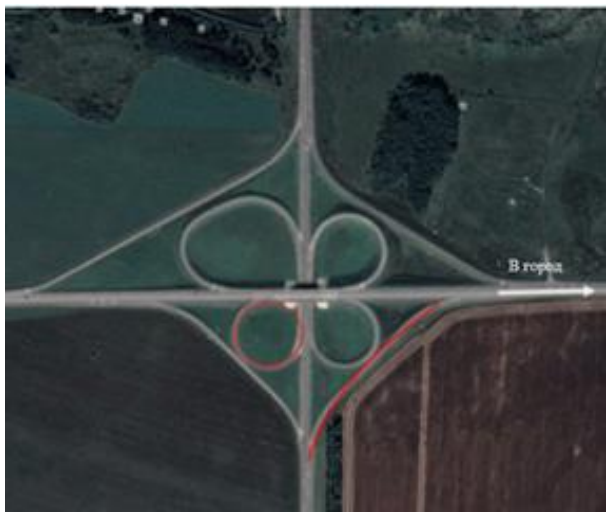

d)

Fig. 1. Transport interchange in the Belgorod region: a) cloverleaf interchange in Razumnoe; $b$ ) cloverleaf junction in Novosadov district; c) tube junction in Severny; d) cloverleaf junction with the M-2 route

\section{Experiment}

According to the analysis of foreign studies, it is established that each type of introductory ramps has its own requirements. To implement the Ramp metering system, the following characteristics are necessary for the study: roadway width, acceleration distance, flow merge distance, radius of curvature, and ramp length $[4,5,6]$. Based on the recommended indicators obtained from the research of Professor Mike McDonald [5], the suitability of the studied sites for the implementation of the Ramp metering system within their borders will be evaluated. Let's summarize the geometric characteristics and parameters of ramps in table 1 and compare them with the recommended parameters. 
Table 1. Comparison of the geometric ramp parameters with the recommended ones

\begin{tabular}{|c|c|c|c|c|c|c|}
\hline \multirow{4}{*}{$\begin{array}{l}\text { Transport } \\
\text { interchange }\end{array}$} & \multirow{4}{*}{$\begin{array}{l}\text { The congress } \\
\text { and its type }\end{array}$} & \multicolumn{5}{|c|}{ Specifications } \\
\hline & & $\begin{array}{l}\text { The width } \\
\text { of the } \\
\text { roadway, } m\end{array}$ & $\begin{array}{l}\text { The distance } \\
\text { of } \\
\text { acceleration, } \\
\mathrm{m}\end{array}$ & $\begin{array}{l}\text { The distance } \\
\text { of the } \\
\text { confluence } \\
\text { of the } \\
\text { streams, } m\end{array}$ & $\begin{array}{c}\text { Radius of } \\
\text { curvature, } \\
\text { m }\end{array}$ & $\begin{array}{l}\text { The } \\
\text { length } \\
\text { of the } \\
\text { ramp, } m\end{array}$ \\
\hline & & \multicolumn{5}{|c|}{ Recommended } \\
\hline & & $4,8 / 3,6$ & $60-200$ & $90-150$ & $\geq 300$ & - \\
\hline \multirow{2}{*}{ Razumnoe } & $\begin{array}{c}\text { External, } \\
\text { cone-shaped }\end{array}$ & 3,5 & 200 & 90 & 600 & 470 \\
\hline & $\begin{array}{c}\text { Internal, } \\
\text { parallel }\end{array}$ & 4,8 & 130 & 100 & 50 & 255 \\
\hline \multirow{2}{*}{$\begin{array}{c}\text { Novosadov } \\
\text { district }\end{array}$} & $\begin{array}{c}\text { External, } \\
\text { cone-shaped }\end{array}$ & 4,6 & 75 & - & 1100 & 576 \\
\hline & $\begin{array}{c}\text { Internal } \\
\text { cone-shaped }\end{array}$ & 4,5 & 33 & - & 50 & 212 \\
\hline Severny & $\begin{array}{c}\text { External, } \\
\text { parallel }\end{array}$ & 3,6 & 200 & 150 & 260 & 230 \\
\hline \multirow{2}{*}{ M-2 route } & $\begin{array}{c}\text { External, } \\
\text { parallel }\end{array}$ & 3,5 & 200 & 150 & 1000 & 400 \\
\hline & $\begin{array}{c}\text { Internal, } \\
\text { cone-shaped }\end{array}$ & 3,5 & 40 & - & 60 & 292 \\
\hline
\end{tabular}

After comparing the geometric parameters of the ramps of each section, we came to the conclusion that the internal ramps at cloverleaf interchanges are not suitable for the implementation of this system due to too sharp turns and a small distance to accelerate vehicles. External ramps have a larger radius of curvature, are more spacious, and usually have a long acceleration lane (over $100 \mathrm{~m}$ ), which meets the recommendations. The cloverleaf interchange with the M-2 highway meets most of the other requirements, but the traffic intensity within the interchange is an important indicator. Interchange in p. Severny is located closer to the city than the interchange with M-2. In addition, the highway turns into one of the largest and most important Central streets of the city - Bogdan Khmelnitsky Ave. Its radius of curvature is $14 \%$ lower than recommended, but this is not a critical disadvantage. The ramp has a fairly long and convenient parallel acceleration lane. In addition, it is much easier to organize a study of traffic flow parameters. Thus, the most optimal section for the introduction of a traffic light control system is a tube-shaped interchange in $\mathrm{p}$. Northern.

Using field studies, we will determine such parameters as the intensity of traffic flow and time delays. It is necessary to determine the peak values of traffic intensity in the direction of the regional center in the studied points of the road network section[8].

Before implementing the exit control system, it is necessary to determine the algorithm of the traffic light object. The local ALINEA algorithm is suitable for this section of the UDS, since there are no other ramps on the section, the configuration of such a transport interchange will not lead to the closure of flows, and this algorithm is adaptive [9]. Configure parameters for this algorithm: location of the transport detector at the exit from the flow confluence zone from $40 \mathrm{~m}$ to $500 \mathrm{~m}$; correction parameter KR; optimal load level of Protected areas; cycle time (from $40 \mathrm{~s}$ to $5 \mathrm{~min}$ ).

Having determined the load levels during the time period under study, we obtained the optimal load of Protected areas $=0.31$. Knowing the indicators of the reduced intensity and the level of loading, we found the value of the control parameter - the rate at which vehicles are released to the Magistral, according to the formula (5) (table 2): 


$$
r(k)=r(k-1)+K_{R} \cdot\left[O_{\text {опт }}-O_{k-1}\right]
$$

where $\mathrm{r}(\mathrm{k})$ - is the control parameter at time $\mathrm{k}$, units/min; Rt- is the control parameter at the previous time $\mathrm{k}-1$, units/min; KR- is the corrective control parameter, units/min; Oопт- is the optimal level of road loading; Ot+1 - is the load level at time $t+1$.

Table 2. Control parameters

\begin{tabular}{|c|c|c|c|}
\hline Time interval $\mathrm{k}$ & $\begin{array}{c}\text { Reduced intensity, } \\
\text { units/min }\end{array}$ & $\begin{array}{c}\text { Existing download } \\
\text { level } \mathrm{O}_{(\mathrm{k}-1)}\end{array}$ & $\begin{array}{c}\text { Control parameter } \mathrm{r}(\mathrm{k}), \\
\text { units } / \text { min }\end{array}$ \\
\hline 1 & 103 & 0,33 & 22 \\
\hline 2 & 115 & 0,36 & 22 \\
\hline 3 & 92 & 0,29 & 22 \\
\hline 4 & 142 & 0,45 & 19 \\
\hline 5 & 176 & 0,56 & 17 \\
\hline 6 & 202 & 0,64 & 13 \\
\hline 7 & 286 & 0,91 & 11 \\
\hline 8 & 158 & 0,50 & 11 \\
\hline 9 & 105 & 0,33 & 11 \\
\hline 10 & 114 & 0,36 & $\mathrm{~T}$ \\
\hline
\end{tabular}

Reduced traffic on the ramp leads to an overall decrease in traffic on the highway. The algorithm keeps the load level at the optimal level. The total load per hour decreased by $10 \%$.

The traffic intensity for the ramp is set by the parameter $r(k)$ based on the load level of the highway, which is implemented using traffic light control. Since there is no traffic light control at the exit, we assume the saturation flow (S) equal to the throughput capacity at the exit $\mathrm{P}_{\mathrm{c}},\left(\mathrm{S}=\mathrm{P}_{\mathrm{c}}=769 \mathrm{u} / \mathrm{h}\right)$, and the duration of the green traffic light signal for a cycle duration of $60 \mathrm{~s}$ is calculated by the formula 2 :

$$
g=\frac{r(k)}{S} \cdot T_{\mathrm{c}}
$$

where $\mathrm{g}$ - is the duration of the green traffic light signal, $\mathrm{s} ; \mathrm{S}$ - is the saturation flow on the ramp, auth/h; $\mathrm{T}_{\mathrm{c}}$ - is the cycle duration, $\mathrm{s}$.

The green traffic light should turn on at the moment when a gap is formed in the right lane of the main stream. To detect discontinuities, it is proposed to use an algorithm based on the condition of providing a double dynamic dimension according to the formula 3 [10]:

$$
L_{d}=l_{a}+v_{a} t_{\mathrm{p}}+0,03 v_{a}^{2}+1
$$

where la - is the length of the car, m; va- is the speed of the car, m/s; Тц- is the driver's reaction time, $\mathrm{s}$.

\section{Conclusion}

Based on all calculations, an algorithm for searching for a gap in the flow is compiled and the throughput part of the control cycle is set (figure 2). This method is used to split a group of vehicles into single ones, thereby increasing the safety of merging streams. 


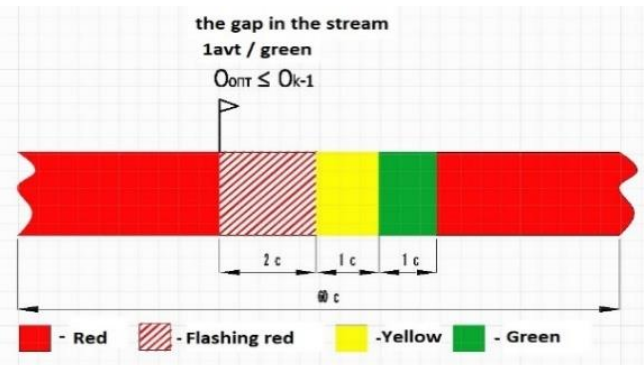

Fig. 2. Total duration of the main cycles.

Installation of this traffic light object is made in accordance with GOST R 52289-2004. The controller Cabinet should be placed in such a way as to avoid the possibility of a collision with a car that has left the roadway, as well as to ensure safe access of personnel to it. It is not recommended to place the Cabinet in the area between the exit and the highway, as well as on the security island. Place transport detectors on the main road at a distance of 40-500 meters from the "nose" of the exit. There should be 2 inductive transport detectors on each lane of the highway. The distance between them should be $6 \mathrm{~m}$ from edge to edge [10].

By implementing traffic light regulation on the site under the control of a feedback algorithm, the existing load will be reduced by $10 \%$. The average time delay per vehicle on the ramp will increase by $27 \%\left(t_{\Delta p}^{\prime}=94,6 s\right)$. As a result of increasing the waiting time for cars at the exit and ensuring their smooth merging, traffic delays on the highway will decrease by $48 \%\left(t_{\Delta \mathrm{M}}^{\prime}=19,1 \mathrm{~s}\right)$.

Installation of this traffic light object is made in accordance with GOST R 52289-2004. The controller Cabinet should be placed in such a way as to avoid the possibility of a collision with a car that has left the roadway, as well as to ensure safe access of personnel to it. It is not recommended to place the Cabinet in the area between the exit and the highway, as well as on the security island. Place transport detectors on the main road at a distance of 40-500 meters from the "nose" of the exit. There should be 2 inductive transport detectors on each lane of the highway. The distance between them should be $6 \mathrm{~m}$ from edge to edge.

\section{References}

1. Zhankaziev S.V. Intellektual'nye transportnye sistemy [Intelligent Transport Systems]. Moscow, 2016.

2. Novikov A., Novikov I., Katunin A., Shevtsova A. Adaptation capacity of the traffic lights control system (TSCS) as to changing parameters of traffic flows within intellectual transport systems (ITS) / in the book: Transportation Research Procedia 2017. pp. 455-462.

3. Shevcova A.G., Mochalina Ju.A. Review of new technical means of road traffic management // Alternative energy sources in the transport and technological complex: problems and prospects of rational use., 2015, T. 2. № 2. pp. 672-677.

4. Bellemans T., De Moor B., De Schutter B. Model predictive control for ramp metering of motorway traffic: a case study. Control Engineering Practice. 2006. T. 14. № 7. pp. 757-767.

5. Zheng P., McDonald M. Evaluation of effects of ramp metering on merging operations. Transportation Research Record. 2007. № 2012. pp. 105-112. 
6. Meng Q., Khoo H.L. A pareto-optimization approach for a fair ramp metering. Transportation Research Part C: Emerging Technologies. 2010. T. 18. № 4. pp. 489506.

7. Gorelov A.M., Vlasov A.A. Managing entrances on highways // Science and technology in the road industry, 2015, № 1 (71). pp. 15-17.

8. Burlutskaya A.G., Shevcova A.G.Concept of development of the "Smart city" system in the transport industry // Organization and road safety, 2019. pp. 298-301.

9. Federal state statistics service [Federal State Statistics Service]. Available at: http://www.gks.ru/wps/wcm/connect/rosstat_main/rosstat/ru/statistics/enterprise/transpo $\mathrm{rt} /$

10. Shevcova A.G., Burlutskaya A.G., Vasileva V.V.Introduction of intelligent transport system ramp metering in the city of Belgorod// World of transport and technological machines, 2018, №4 (63). pp.42-48 